Article

\title{
Rethinking Suburban Governance in the CEE Region: A Comparison of Two Municipalities in Poland and Lithuania
}

\author{
Jurga Bučaitè-Vilkè ${ }^{1, *}$ and Joanna Krukowska ${ }^{2}$ \\ ${ }^{1}$ Department of Sociology, Vytautas Magnus University, 44248 Kaunas, Lithuania; E-Mail: jurga.bucaite-vilke@vdu.It \\ 2 Department of Local Development and Policy, Faculty of Geography and Regional Studies, University of Warsaw, \\ 00-927 Warsaw, Poland, E-Mail: jkrukowska@uw.edu.pl
}

* Corresponding author

Submitted: 15 June 2020 | Accepted: 4 September 2020 | Published: 3 December 2020

\begin{abstract}
In this article, we seek to analyse and compare the modalities of suburban governance in Polish and Lithuanian municipalities looking at the territorial development trends typical for the Central Eastern Europe region. The theoretical elaborations on suburban governance are evolving towards the analysis of constellations of diverse actors, institutions and processes that define the politics and design of suburban spaces. We assume that there are similarities and differences in suburban governance in the analysed localities compared to Western countries in terms of networks, actors and territorialisation of local politics. Despite both suburban municipalities showing similarities in suburban development patterns (growing middle-class population, economic capital accumulation, suburban sprawl and interconnectedness with the metropolitan zone), the analysis reveals the main differences in terms of composition and importance of horizontal and vertical networks, the role of local stakeholders and collective action. The article concludes that both localities represent a specific approach to suburban governance marked by low stakeholders' participation, dependence on the top-down vertical state and regional networks and the creation of urban-suburban policies within metropolitan areas.
\end{abstract}

\section{Keywords}

local government; social mobilization; suburban governance; suburban municipalities

\section{Issue}

This article is part of the issue "Cohesion in the Local Context: Reconciling the Territorial, Economic and Social Dimensions," edited by Anja Jørgensen (Aalborg University, Denmark), Mia Arp Fallov (Aalborg University, Denmark), Rikke Skovgaard Nielsen (Aalborg University, Denmark), Hans Thor Andersen (Aalborg University, Denmark) and Maja de Neergaard (Aalborg University, Denmark).

(C) 2020 by the authors; licensee Cogitatio (Lisbon, Portugal). This article is licensed under a Creative Commons Attribution 4.0 International License (CC BY).

\section{Introduction}

The article takes inspiration from the territorial governance concept established in the broader theoretical discussion on the neo-institutionalism perspective in analysing governance routines, networks, mechanisms and practices (Healey, 1999, 2004; Jessop, 2000, 2002; Lowndes, 2001). Governance institutions underline the character of formal and informal collective action looking at the relations between citizens, stakeholders and other actors (Lowndes, 2001). An extensive research lit- erature indicates that territorial governance is used as a specific term that refers to the interaction between governance networks, practices and routines in urban (or metropolitan) and rural spaces (Davoudi, Evans, Governa, \& Santangelo, 2008; Le Galès, 2002).

Our article traces the mechanisms and modalities of suburban governance. The suburbanity and suburbanisation processes manifest the decentralisation of power, redistribution, segregation and inclusiveness, changing the patterns of urban-suburban interactions, forms and contents (Ekers, Hamel, \& Keil, 2012). It is important 
to discuss the different forces that shape the transformation of suburban governance, considering political, economic and social dynamics. Regional differences are also significant. The existing literature demonstrates that it is a difficult task to trace down the regional socioeconomic and political forces shaping suburban governance processes. Our article is oriented towards addressing the literature gap on the Central Eastern Europe (CEE) suburban governance schemes and practices. Can we refer to specific modes of suburban governance in the CEE region? What are the governance practices, policies, actors and networks that lead to the suburban character? What are the similarities and differences of suburban governance compared to Western countries when it comes to how we understand the qualities of suburban places considering the territorial and functional interconnectedness with urban zones? From the urban governance perspective, we elaborate on the understanding of suburban governance considering vertical and horizontal networks, actors and arenas. Our main hypothesis relies on the assumption that the suburban municipalities in the CEE region have their specific 'suburban' approach to governance in terms of actors, roles, strategies, interests, networks and discourses.

The article uses the comparison of two municipal cases in two countries that had experienced similar institutional paths concerning economic growth and territorial cohesion policies since the EU accession process in 2004 as a part of the CEE region: the Kaunas district municipality in Lithuania and the municipality of Pruszcz Gdański in Poland. The selected municipal cases (one municipality in each country) represent suburban characteristics such as urban sprawl, interdependence within metropolitan zones, overlapping public services infrastructures and different horizontal and vertical interpolicy coordination mechanisms. We use the qualitative datasets from the fieldwork in suburban Lithuanian and Polish localities (municipalities) collected in 2019. The interviews were performed with the local authorities, businesses and community stakeholders to deconstruct the territorial understanding and discourse of territorial place-based policies.

The article is organised as follows. First, the theoretical assumptions on territorial governance and suburban spaces are discussed, drawing the contextual background of vertical and horizontal coordination networks, a variety of local actors and collective action. The research outline brings a comparative basis for the methodological framework to analyse both suburban municipalities in Poland and Lithuania. Subsequently, the contextual factors of suburban localities turn to the empirical suburban governance analysis focusing on the local governance actors, arenas, vertical and horizontal coordination modes and collective action in the two case studies. The article provides tentative conclusions explaining the differences and similarities of suburban governance in CEE region compared to Western processes of suburban development.

\section{Theoretical Framework: Territorial Governance and Suburban Places}

The concept of territorial governance and the shift from government to governance or multi-level governance opens the broader theoretical discussion on collective territorial action, local democracy and mobilisation (Rhodes, 2000). Territorial governance is understood as "the process of territorial organization of the multiplicity of relations that characterize interactions among actors and different, but non-conflictual, interests" (Davoudi et al., 2008, p. 37). Additionally, the ESPON report interprets the concept of territorial governance through the dimensions of coordinating actions of inter-related actors and institutions, integrating policy sectors, mobilising stakeholders, adapting to territorial context and realising territorial specificities (ESPON, 2014). The definition is based on the integration of the decision-making process. The main challenge of urban sociology and spatial planning analysis is to develop a consistent framework for analysing governance mechanisms and practices in areas that promote their specific suburban forms of coexistence.

\subsection{How to Integrate Territorial Governance and Suburban Spaces?}

If we look at the territorial governance approach, there are different interpretations of how to operationalise the concept (Atkinson, Tallon, \& Williams, 2019; Jessop, 2002). In general, four territorial governance issues are essential: vertical coordination, horizontal coordination, the participation and involvement of social stakeholders' interests and territorialised collective actions (Davoudi et al., 2008). Vertical coordination refers to the principle of re-scaling and subsidiary in self-governance systems. It also indicates the allocation of decision-making power to different governmental scales for implementing decentralisation policies in countries (Sellers \& Lidström, 2007). The horizontal coordination dimension underlines the networking and collaborative mechanisms among different local-level stakeholders and actors. The integration of different territorial assets and resources and implementation of sectoral, local policies are linked to the vertical subordination as well as involving a variety of central and municipal actors (multi-level governance). The participation dimension is connected to the involvement forms and strategies used by stakeholders and policy actors. Here, the capacities and resources are necessary for the decision-making and implementation processes of local welfare policies. Finally, the aspect of territory as a decision-making arena in linking territorial governance, local assets and collective action is important.

In the contemporary world, the suburban spaces are expanding in territorial and cultural sense (Ekers et al., 2012). The theoretical discussion noticed that suburbanisation leads to economic, political, social and spatial expansion. The suburban sprawl overwhelms the 
metropolitan discourse with the fast growth of capital, human resources and changing modes of the relationship between local-region and state. The critical point turns to the lack of consistency in suburban planning processes and decentralisation processes in Eastern Europe (Hirt, 2007; Hirt \& Petrovic, 2011).

\subsection{Suburban Governance in the CEE Region}

It is impossible to formulate a universal framework for the analysis of territorial governance modes in suburban areas. The term 'suburban' seems rather abstract and aggregates extremely different processes and socioeconomic contexts. Various authors emphasize that there is more than one universal global definition of 'suburbanity' (Ekers et al., 2012). We can instead do it for the specific groups of regions and countries. Even within the European Union, the suburban context is very different. Some suburban processes are very similar in the CEE region compared to those observed in Western Europe: dynamic immigration and spatial development increase in the share of the urban and sub-urban population within the society. However, there are also significant differences, i.e., up to the beginning of the 21st century, most of the CEE suburbs had not experienced ethical diversity. Besides, unlike most of the EU countries, the CEE after the economic transition has not developed advanced spatial planning instruments of integrated and legally binding agglomeration plans. It results in the relatively spontaneous development of the suburban spaces and urban divisions, for example, gated communities (Blinnikov, Shannin, Sobolev, \& Volkova, 2006; Hirt, 2007; Hirt \& Petrovic, 2011; Stoyanov \& Frantz, 2006) and intensification of urban sprawl. For many years, the CEE metropolises have been functioning rather as a simple aggregation of the core city and neighbouring municipalities with no direct emphasis on strategic and spatial coordination of the policies. Suburban processes in the CEE context are a mixture of metropolisation coordination (where suburban municipalities are instead a supporting actor) and neoliberal thinking.

Thus, when trying to merge different dimensions of territorial governance contexts with the European suburban specificities described in the literature, we should keep in mind several contextual differences between the best-described Western European suburban areas and the CEE context (e.g., Hess, Tammaru, \& Leetmaa, 2012; Krisjane \& Berzins, 2012):

- relatively low importance of ethnic issues, minority conflicts are rare or absent;

- economic collapse after 1989 and rapid growth after the accession to the EU in 2004;

- weak and unstable spatial planning standards, often resulting in urban sprawl;

- high emigration rate after the 2000s, mostly from rural areas to the big cities or abroad.

\subsection{Analytical Perspective for Suburban Governance Analysis}

For analytical purposes, we refer to Patsy Healey's (2004) perspective on governance as a collective action mode. The analytical levels demonstrate continuous interactions within governance networks and actors, including local arena specificities, governance processes and governance culture (for an adapted summary, see Table 1.).

The first dimension of the local arena looks at the variety of actors, roles and interests in territorial governance. In suburban cases, the suburban actors are highly

Table 1. Suburban specificities of territorial governance.

\begin{tabular}{lll}
\hline Level & Dimension & Suburban context in the literature \\
\hline $\begin{array}{l}\text { Local arena } \\
\text { specificities }\end{array}$ & Actors & $\begin{array}{l}\text { High dynamics, urban sprawl, diversification of actors (old versus new } \\
\text { inhabitants, ethnic conflicts), diversified territorial identity, high } \\
\text { expectations regarding public service delivery }\end{array}$
\end{tabular}

Arenas

Territorial Vertical coordination governance processes
Weak local arenas, social life concentrates in the core city(-ies)

Unstable networks, coalitions beneath and above territorial borders, a strong influence of above-local actors (e.g., big companies), the strong influence of above-local policies (e.g., national, sectorial) shaping the local discourse

Horizontal coordination

Strong metropolitan (urban-suburban interconnectedness) coordination

Participation and involvement of social stakeholders' interests

Territorialised collective actions
Low involvement on local policy co-creation

Diverse according to metropolitan governance standards (level of local suburban autonomy, the scope of above-local tasks)

Source: Authors' elaboration, adapted from Davoudi et al. (2008), Ekers et al. (2012), Faludi (2012) and Healey (2004). 
diversified and decentralised. Suburban policy actors are municipal inhabitants, business sector, NGO and local administration understood as officials and elected representatives. The literature of suburban governance concentrates mostly on the social contextual specificities of municipalities suffering from fast urban sprawl and immigration and spots light on the potential conflicts between groups of citizens. On the one hand, the 'new metropolitan class' of the suburban society is composed mostly of relatively young, affluent and educated people (Swianiewicz \& Lackowska, 2008). However, according to the literature, their territorial identity is above local; they identify with the whole metropolitan area more than their suburban municipality. Sometimes their mobility and openness result in a kind of 'de-localized' identity of a "creative class" (Florida, 2002).

On the other hand, suburban citizens are also those living in the same place for decades, often representing post-rural families. The suburban arenas face the typical problem related to both under-bound (family) and overbound (above-local) catchment areas (Bennett, 1997). The same problem may concern, e.g., the local business sector: Many locally based enterprises can be oriented on the regional and metropolitan market, thus less interested in local politics.

Secondly, the governance process means access to power and forming governing coalitions in the territory (Healey, 2004, p. 93). The literature on suburban political elite's behaviours and formation is relatively scarce. Acritical aspect specific to suburban governance schemes is the relatively high dependence of abovelocal actors' policies and decisions made outside the municipal borders. Suburban municipalities are strongly dependent on the national framework for metropolitan/agglomeration coordination and the scope of available spatial policy tools (or a lack of it) is decisive, e.g., urban sprawl control. Besides, the suburban economy relies on the broader socio-economic context of the agglomeration, where the policy conducted by the core city(-ies) plays the leading role. Thus, operation within various vertical and horizontal networks is the crucial importance of suburban areas.

\section{The Research Outline}

\subsection{Comparative Background}

As it was suggested in the previous sections, the study aims to confront the processes and specificities of suburban governance suggested by different scholars with the two municipality case studies from the CEE region. We assume that there are suburban governance practices that can be compared in different contexts in terms of governance patterns, networks and actors in different places. From the other point, the national socialeconomic and demographic factors and circumstances and local political decisions might also bring a different approach to the adaptation of suburban understanding of place. Referring to the dimensions of territorial governance listed in Table 1, we propose the following set of research questions that allow looking at comparative contexts in two suburban localities (Ekers et al., 2012; Healey, 2004):

- What types of local actors and stakeholders can we identify in suburban territories?

- How is the process of governing coalitions and network formation organised in suburban municipalities?

- What are the relations with the metropolitan area and the other upper-level administrative or political actors in two municipal cases (in horizontal and vertical perspective)?

- How does it differ from the patterns and mechanisms described in the suburban governance literature?

\subsection{Empirical Dataset and Selection of Cases}

To answer the questions on suburban governance modes, we use the empirical dataset based on a research project implemented in seven EU countries (Denmark, Greece, Italy, UK, Austria, Poland and Lithuania). Among the other research activities, the project methodology envisaged qualitative research in suburban, urban and rural municipalities in each participating country (LAU level municipalities). The research was carried out in one large metropolis in each country, one suburban and one rural locality (municipality). Our article focuses on the suburban municipalities in two participating countries, Poland and Lithuania. Selected municipalities represent the diversity of suburban development concerning territorial capital, local stakeholders' involvement and local governance arrangements. In Lithuania, we selected Kaunas district municipality for the suburban case, which represents a sizeable outer ring municipality characterised by the fast-growing population and outward commuting networks via the metropolitan area. In Poland, we have chosen Pruszcz Gdański, one of the leading satellite localities of the Tricity (Gdańsk-GdyniaSopot) metropolitan area in the Pomerania region.

Following project methodology, 33 semi-structured interviews were carried out in total: 20 in Kaunas district municipality, 13 in the municipality of Pruszcz Gdański. In each locality, the interviews were conducted with the community stakeholders (community organisations, NGOs), business stakeholders and public authorities (municipal officials involved in planning, business relations, municipal officials and state institution representatives). In both countries, the interviews were carried out in June-September of 2018. Semi-structured interviews were conducted following the synchronised interview guidelines for all countries dedicated to all three groups of respondents. Our article focuses only on the aspects of territorial governance that permit us to define the similarities and deficiencies of suburban char- 
acter in both countries. The other part of the article gives more answers to the theoretical assumptions defined in our comparative framework.

\section{Case Studies' Local Context}

The article focuses on two different suburban municipalities in Poland (Pruszcz Gdański municipality) and Lithuania (Kaunas district municipality) that turn to a comparison of several suburban characteristics. The research outline presents the justification for the selection of the cases in both countries.

Kaunas district municipality surrounds the metropolitan area of the second largest city of Kaunas in Lithuania. Kaunas district municipality is one of the largest suburban municipalities in the country, with a population of 96,441 thousand inhabitants in 2020 . It has strong interrelatedness with the metropolitan area of Kaunas city in terms of urban governance, public services, infrastructure and local population flows. In this sense, both urban and suburban municipalities have a significant potential for investments and the potential for creating polycentric urban districts and functional transportation systems, the programs for the renewal of residential districts and the use of cultural potential and active local communities. It is also an example of significant suburban demographic growth. The most considerable population growth was between 1996 and 2019, which reached $17.42 \%$ compared to other municipalities according to the national statistical data. The more significant number of arrivals is explained by the fact that young families started to move to the suburbs because of rapid private housing development projects. In the Kaunas district municipality case, the municipality-led suburbanisation process turned to the problems of deliberate planning of housing and recreation zones, market infrastructure development and effective land use, especially in the zones close to the metropolitan city. The dominant narrative around local territorial assets within Kaunas district municipality are those that one might expect to find in post-soviet conurbations in the CEE region, one that has extensive economic development indicators.

In what concerns the Polish case, Pruszcz Gdański is a suburban municipality of 30 thousand inhabitants located within Tricity metropolitan area in Pomerania region (South Baltic coastline). The municipality neighbours the city of Gdańsk - the core of the TriCity. Pruszcz Gdański is a suburban town and an important node in a regional settlement network - the town is an administrative centre of a county composed of eight municipalities and counting more than 110 thousand inhabitants. It is also a centre of economic activity. It is very well connected to the metropolitan core (via the A1/S6 Highway, National Route 91 and the railway). Both natural population change and net migration rate are positive, with apparent domination of the latter in the overall population growth. Thanks to the suburban location, the population over the last 10-15 years more than doubled. This trend should continue in the following decades as the locality is a part of an intensively suburbanising area and commuting zone of the metropolitan core. Secondly, Pruszcz Gdański is an important centre of economic activity and is characterised by an absorbent labour market. The location near the seaport and main transportation corridors makes it a particularly attractive location for logistics companies and distribution centres. The indicators of the personal income also place Pruszcz Gdański among the most affluent localities in the region. Apart from the private sector, the military air force's base is located there with plans to be developed. Pruszcz has huge and developing investment areas. Pruszcz as a 'southern gate' to Gdańsk City and is taking the benefits of this position. As in the Kaunas district case, the internal migration drives the development of urban infrastructure, creates demand for public services and is beneficial to the labour market. Although most new residents are young people, the locality is no stranger to the problem of ageing. The issue of the elderly is increasing in Pruszcz Gdański. It becomes more important than the 'classical' scope of social service (poverty, etc.). Considering the territorial bottleneck, the most crucial challenge for the locality is roads and public transport. Another challenge is to catch up with the suburbanisation processes with adequate spatial management tools and plans to control it better.

\section{Results}

\subsection{Perception of Local Governance Actors and Arenas}

\subsubsection{Actors}

\subsubsection{Local Authorities}

Referring to local authorities' participation in suburban processes, one could focus on a different interpretation of roles and interests in suburban-driven policies. Local municipal authorities and mayors are those that pay attention to various local actors and their benefits. The modes of coordination and management might vary between both suburban localities.

In Kaunas suburban locality, the municipal administration and the mayor are considered the main actors in territorial development policies. The municipality uses a sectoral approach to meet the territorial needs, focusing mainly on welfare services, education and quality of public infrastructure. The elderships (territorial subunits of municipal administration) that have some autonomy in small-scale decisions, but are mostly dependent on the municipality or central government's programs, funding and plans, still play a critical role in connecting the functions of municipality and locality needs. As interviews indicate, the local authorities are responsible for the inter-organisational collaborations and private-public partnerships in the locality. According to the local strategic development plan, the local insti- 
tutional networking is enacted using private initiatives, non-governmental organizations, and promotion of voluntary work for integration of socially vulnerable groups or individuals.

In Pruszcz Gdański, the political leader (mayor) is often mentioned as a critical asset of the commune thanks to his vision, determination and courage in applying for the external funds. He has been re-elected four times since 2002 with very high support (83.5\% support in the last election in 2018 with $55.4 \%$ turnout). Local politics is perceived as very much mayor centred. Despite local government declarations, our interviewees assess that local administration does not partner from outside the town hall in the policymaking process. Moreover, the local government is not expected to do so. As one local businessman put it: "We all have our job to be done; we work in different areas." Other interviewees clearly express their expectation that local authorities should act on their own in a purely administrative manner. Some of the local politicians (councillors) see themselves as reviewers rather than co-creators of policy, which should be developed by the mayor.

Moreover, the local authorities (mayor and deputy mayors) are not interested in stimulating new publicprivate initiatives. They declare being afraid of decreasing transparency in consequence of the governance style of policymaking. Despite some financial difficulties in catching-up investment needs, it is much easier to conduct investments independently than in a different kind of partnership.

\subsubsection{Business Actors}

The involvement of business stakeholders and public/private partnerships are also necessary for the design and implementation of the suburbanisation process in terms of capital accumulation and flows (Ekers et al., 2012).

In the Kaunas district municipality case, the main business actors are large industrial companies located in Kaunas Free Economic Zone that operates as the largest employer in the region with more than 5 thousand employees and 24 foreign companies in 2020. Referring to business actors, the main factors that foster suburban entrepreneurialism are related to strong inter-organisational networks within large companies in Kaunas Free Economic Zone and their small and medium-sized subcontractors (Kaunas suburban business actor). Nevertheless, the other business actorsuburban small and medium businesses-are not always actively involved in local policies because the municipality and elderships do not often invite entrepreneurs to the public meetings or discussions on critical local issues. The interviews demonstrate that the lack of a shared understanding of public interests and ineffective negotiations between the municipality and businesses limits entrepreneurs' initiatives from a more active role in territorial development (suburban business actor). Only a small number of local entrepreneurs take a proactive role in suburban development policies.

In Pruszcz Gdański, the leading employers among large companies are LPP (retailing company logistics centre), Poczta Polska (the distribution centre of the national postal operator), Crown Packaging and Smurfit Kappa (international producers of packaging). Many local smallsized enterprises accompany them. The general assessment of the involvement of entrepreneurs in co-creating local policies and management is unclear. Some interviewees see that entrepreneurs are not involved in making the policies. Contacts of local municipalities with local business sectors are incidental, mostly informal, and described as 'responsive' - they occur when the specific problem is to be solved. They only cooperate in consulting the schedule of public investment processes. There is a problem in mobilising broader collective action in the local business environment. The interviewees do not blame local authorities for the low involvement of the local business sector. There are two most frequently indicated reasons for this: on the one hand, local firms are too big (thus, not interested in local politics) or too small (therefore, concentrated on day-to-day operations) to get involved in policymaking. On the other hand, the local administration scope of tasks is not attractive for the business sector; they do not expect much from the public sphere.

\subsubsection{Role of Local Social Actors and Citizens}

Low level of community participation and social stakeholders' involvement is typical for both suburban municipalities. Our interviews demonstrate that civic engagement's bottom-up effects are understood as a matter of minor importance in both localities. The shortage of leadership and expertise of local community activists is treated as the main impediment to the successful implementation of public services.

In Kaunas suburban locality, the main social actors are local community centres (more than 20 organisations) and NGOs' operating in the welfare services. Kaunas district Community Council and NGO Council initiated by local authorities, provide an essential arena in expressing community voice to suburban development. Community stakeholders focus on territorial activation projects, the efficiency of collective mobilisation, the importance of local leadership and improving access to local welfare services. The impact of local communities and activists refers to small-scale interventions related to cultural projects, public infrastructure and the provision of public services (public transport, recreational zones, street maintenance and care for the elderly).

In Pruszcz Gdański municipality, there are more than 70 recognised local associations active in various fields (sports clubs, education, culture, social care, tourism, ecology and sustainable development). Surprisingly, the role of community actors in the provision of local public services is minimal. The only exception in social care, e.g., 
mentally disabled people and seniors. The most active is the local senior citizen community, represented by three organisations and a council advising the mayor. The municipality prepares, adopts and implements yearly plans of cooperation with local NGOs (required by national law). These plans are used mainly to define the basic rules of the bids for public funding distributed by the municipalities to the NGOs. However, many interviewees expressed dissatisfaction with the degree of selfcommitment and self-organisation of the inhabitants. The activeness of local leaders and public actors in organising is coupled with a general willingness to participate. Generally, local society is commonly perceived as very integrated with no clear divisions nor conflicts.

\subsubsection{Arenas}

Local arenas focus on the spaces of collective interactions. In suburban territories, the local arenas might differ in terms of how deliberative efforts are organised. In both cases, the mobilisation of the collective action reflects weak civic resources and traditions.

In the Kaunas district municipality case, the local deliberative arenas are less critical for collective decisions. In dealing with the changing suburban context (the increasing population of young families with kids, industrial zones, growing economic productivity and explosive development of suburban residential areas), Kaunas district municipality uses occasional deliberative practices for local stakeholders, for example, public discussions, deliberations and meetings with citizens. As interviews with local authorities reveal, the elderships are responsible for the formal communication with various stakeholders' groups; for example, they initiate formal meetings and debates with inhabitants to discuss territorial development plans.

In general, in the Polish case, local governance processes are powerfully concentrated within the town hall. There are only several exceptions from this rule. Surprisingly, it seems that the most crucial lobbying group is senior citizens. The Third Age University (run by an NGO) is a thriving organisation with approximately 400 students. The Council of Senior Citizens serves as a consultation body in the town hall. Its role is to represent the needs of senior citizens and their organisations. It puts forward initiatives aimed at integrating the senior community (meetings, events) and providing better health care for them, but it does not seem to play an essential role in policymaking. Apart from that, there are no other institutionalised territorial cooperation arenas. For several years, the mayor has organised a regular (once per year) Christmas meeting for local businessmen, but it does not play a role of a regular consultative platform. It is rather treated as an occasion for building horizontal inter-sectorial business relationships.

Finally, the comparison of both suburban cases (summarized in Table 2) emphasises the challenging context impeding the formulation of inclusive local development strategies. Suburban territories are organised around different spaces within the lack of functional interconnectedness, especially between business and civic actors. Suburban business actors focus on economic capital accumulation and growth coalitions. Local public authorities, including the mayor, face regional and state regulations on different issues (spatial segregation, housing policy, public services delivery, infrastructure development and economic growth).

\subsection{Perception of Local Governance Schemes}

The main question analysed here involves the mechanisms and arrangements of suburban governance, collaborations and coordination of local networks and relations with the other actors important for suburban policies. What is the level of the above-local binding of local policies and their horizontal coordination? What is the role of local stakeholders involved in territorial governance and policymaking? We look at different perspectives of community, local governance and business stakeholders in Polish and Lithuanian suburban municipalities to reveal the diversity of territorial governance perceptions. First, the suburban mechanism of local networks and coalitions is essential for both localities. The qualitative interview data indicate that it is possible to distinguish between vertical and horizontal suburban coordination modes and decision-making. Secondly, territorialisation

Table 2. Actors and arenas-the main characteristics of the case studies.

\begin{tabular}{lll}
\hline Suburban governance dimensions & Lithuanian locality & Polish locality \\
\hline Actors & High importance of local municipal & Powerful multi-term mayor, entrepreneurs, \\
& $\begin{array}{l}\text { administration and directly elected } \\
\text { mayor, suburban entrepreneurialism, }\end{array}$ & many NGOs of moderate activity, integrated \\
& weak NGO, active local communities & $\begin{array}{l}\text { local society, low involvement in } \\
\text { policymaking, strong senior citizen } \\
\end{array}$ \\
& & bottom-up activism
\end{tabular}

Arenas

Concentration on top-down initiated arenas, limited cases of bottom-up deliberative arenas.
Concentration of governance processes, the only formalised cooperation arena is the Senior Citizen Council

Source: Authors' elaboration based on interviews with stakeholders in analysed municipalities. 
is an important factor for identifying programs, projects and initiatives that stimulate the territorial approach (Davoudi et al., 2008, p. 38).

\subsection{Horizontal Networks}

On the horizontal level, formal and informal interorganisational networking and interconnectedness are important for different issues, for example, economic development and urban regeneration programs. Thereby, the suburban relations with the metropolitan city reflect the functional symbiosis, for example, public services, infrastructure and transport provisions (Ekers et al., 2012; Young \& Keil, 2010). The relations with the core city reflect the internal policies of organising point public services provisions and overlapping infrastructures. In Polish and Lithuanian localities, the inter-municipal cooperation is organised autonomously from state policy, creating their suburban narratives of welfare provisions, commuting networks and capital accumulation.

Both suburban localities reveal differences and similarities in organising horizontal networks. In the Lithuanian case, horizontal coordination and collaboration mostly focus on developing area regeneration and public infrastructure projects in cooperation with the metropolitan area. Data from the suburban locality also reveals that the main actors in horizontal networks are urban-suburban municipal administrations, mayors and elderships that tangle between top-down and bottom-up approaches. The municipal administrative sub-divisions (elderships) play a central role in facilitating the process of suburban governance issues. As local authorities notify, Kaunas district municipality and elderships make efforts to reconcile local community needs and public services delivery infrastructures.

In the locality of Pruszcz Gdański, we observe diverse types of horizontal inter-municipal cooperation networks. The best known in the area is the Association Metropolitan Area Gdańsk-Gdynia-Sopot (MAGGS), gathering three core cities of the conurbation, eight counties and 45 smaller municipalities of the area. A 20-year long history of more or less successful competing and overlapping metropolitan networks ended in 2011 with the establishment of the MAGGS. The actual stimulus for this was the formal requirement to create one coordinated metropolitan structure to get the EU funds available under the Integrated Territorial Investment framework 2014-2020. However, metropolitan coordination of sectoral policies is still at a very early stage.

Pruszcz Gdański also cooperates with neighbouring municipalities. Surprisingly, the relations with the ring rural municipality of Pruszcz Gdański are not intense, not regular, but assessed instead as "proper and correct." Most inter-municipal projects occur within bilateral and multilateral agreements: with Gdańsk (public transportation) and Kolbudy (a project of common metropolitan school).

\subsection{Vertical Networks}

The vertical dimension of territorial governance refers to the hierarchical arrangements between central authorities and municipalities in implementing different policies (e.g., active labour market, urban regeneration, or economic growth policies). In Lithuanian and Polish cases, the regional context and impact of the state policy on suburban governance are significant in designing policy instruments and territorial discourses. The main difference turns to the configuration of self-governance systems in Poland and Lithuania that produces the suburban governance processes.

In the Lithuanian case, the data from the interviews reflect the recent discussion on the self-government autonomy level in Lithuania. Questions on fiscal autonomy of municipalities, financial self-reliance, policy scope, institutional depth, political discretion and shared-rule factors (Ladner, Keuffer, \& Baldersheim, 2016) become the main topics in the interviews with suburban business and local authorities' actors. In Lithuania, the municipalities have relatively low financial selfreliance and fiscal autonomy that limit the implementation of large-scale investment projects. According to interviews, the coordination and supervision between municipality administration and state authorities is crucial. One of the examples of vertical coordination noticed by respondents is municipal fiscal policy and municipal budgeting procedures. Many governance actors (e.g., public authority actors) use the case of the disintegration of strategic visions on sustainable suburban zones development and central government regulations on the construction process and private investments to real estate.

Contrastingly, the vertical division of powers in the Polish three-tier local government system put the most considerable emphasis on the municipal level. Municipalities are the strongest among the three administrative levels in terms of financial resources per capita and the only having any own revenues. However, this does not mean that relations with the county and the region are not necessary. Conversely, thanks to the relatively high position of municipalities, the vertical relations are perceived as balanced and realised, keeping the partnership's good practices. The municipality conducts several investment projects with the county (as it is its capital). Cooperation between the municipality and the office of an elected regional government is very intense, and it concentrates on the implementation of the EU funds projects since the regional government is managing their regional part. Another often and spontaneously indicated contact is national transportation companies, notably the National Railway. As the mayor of Pruszcz Gdański, the county governor and the regional government are rather associated with the national opposition party; most of the unfavourable decisions made at the national level (concerning, e.g., railway transportation) are explained by the political conflict. 


\subsection{Participation and Involvement of Social Stakeholders' Interests within Territorialised Collective Actions}

The participation and involvement of social stakeholders represent the scope and number of different interests involved in suburban governance. If the agreements between stakeholders are formal, it might lead to greater accountability and satisfy the needs of a wider community (Davoudi et al., 2008). It is essential to consider how local stakeholders define and prioritise actions that benefit suburban territories. Finally, the aspect of territory as a decision-making arena in linking territorial governance, local assets and collective action is essential. Both localities demonstrate the importance of bottom-up initiatives to identify the specificity of suburban territory.

Kaunas district case demonstrates that collective engagement is very active in fostering the small-scale projects on environmental issues or public services provision. Local actors can increase the quality of life by small-scale projects, donations and initiatives but cannot mobilise as a political force with a higher impact on strategic planning. A part of suburban residents is middleclass professionals with capacities for collective mobilisation, especially in the areas of urban-suburban public services availability (e.g., public transportation, preschool system). The collective efforts are concentrated on a territorial level and mostly focus on the increasing living quality standards, such as the renovation of recreational zones in elderships (community representative). The social stakeholders underline the limited impact of collective mobilisation and cannot implement large-scale projects or use formal channels of collective actions.

The interview analysis results that in the suburban locality in Lithuania, the attachment to the specific geographical territory is essential. The collective actions of local stakeholders emphasize particular territories within the municipality geographical boundaries that require more specific economic investments. For example, urban regeneration and economic growth policies are based on the distinction between more urban and rural elderships that need different policy coordination approaches to tackle social exclusion. Another aspect that fosters territorialised collective actions is the functional autonomy of the elderships. Most of the locality stakeholders argue that the municipality needs to reconsider the public services implementation and provide more responsibility to the elderships that recognise the local needs (community representative).

In what concerns the Polish case and territorially adapted policies, there are only several cases of a truly territorialised and individualised local policies. Most local societal initiatives are micro-scale events aimed at building local identity. The town hall initiates most of them, but there are also examples of bottom-up initiatives undertaken by local leaders, such as documenting the history of the area, the stories of post-war settlers, lobbying for school patrons of domestic origin, or organising cultural and leisure activities. Apart from that, the interviewees declare a rather low and superficial role of public participation of consultation. The most vivid participatory process has been organised for the preparation of the local regeneration plan. In addition, as the municipality failed to acquire financial support (because it is too wealthy to meet the regional financial support criteria), the future of the local regeneration plan is unsure. As it is now, the program is focused on improving public space in the centre with hard investments in infrastructure. It is mostly a local government program, which is implemented by local government administration. A similar concentration of the planning processes within the town hall can be observed in the case of regular spatial planning procedures. A new form of including and frame citizens' needs are the opinion polls among the residents.

Table 3 summarises the vertical and horizontal networks and governance processes in Polish and Lithuanian

Table 3. Networks and governance processes-main characteristics of the case studies.

\begin{tabular}{lll}
\hline Suburban governance dimensions & Lithuanian locality & Polish locality \\
\hline Horizontal networks & Strong metropolitan cooperation in & Weak and incidental metropolitan \\
& public services and infrastructure & cooperation, metropolitan school with \\
& provision, emerging conflict zones, & neighbouring municipalities, weak \\
& high importance of municipal & horizontal contacts
\end{tabular}

administrative sub-divisions

(elderships) in horizontal ties

Vertical networks

Participation and involvement of social stakeholders' interests and territorialised collective actions
High importance of state authorities, low autonomy level in organising territorial policies

Low capacity of local activism, territorial identity.
High significance of the region and the county, the key decisive role of the national railway company (conflicts)

Incidental actions, failure of the Local Renewal Plan initiative, territorial initiatives are sporadic

Source: Authors' elaboration based on interviews with stakeholders in analysed municipalities. 
localities. The cases reveal strong inter-municipal cooperation in terms of public infrastructure, economic capital flow and service delivery approaches. In both countries, the state authorities do not regulate specifically the modes and mechanisms of urban-suburban cooperation.

\section{Conclusions: Suburban Understanding of the Governance and Territory}

Summing up the theoretical debates of territorial governance, the dimensions of the participation and consensus-building among public and private actors, the devolution of powers and resources to lower levels of decision-making and territorial cohesion implementation could be identified (Stead, 2014). The article focuses on the relational approach of territorial governance that refers to the hierarchical and/or vertical arrangements between suburban actors in defying 'suburban character.' Our assumption relies on identifying parameters of suburban governance in the CEE region compared to the experience in Western countries.

The article analyses two suburban localities reflecting the trend of intensive suburban sprawl and an increasing number of middle-class families, economic capital accumulation and inter-connectedness with metropolitan areas. Summarising the main dimensions of suburban governance cases in Polish and Lithuanian localities, we could distinguish a few main conclusions in terms of local authorities, business and social actors' participation, horizontal and vertical network coordination and territorialised collective actions (Davoudi et al., 2008; Healey, 2004). Compared to similar research in Western countries, the parameters we find in Polish and Lithuanian cases can refer to the regional specificity of suburban governance mechanisms. However, we keep in mind that the conclusions based on the analysis of only two case studies can only be tentative.

Among suburban governance characteristics, we can highlight the similarities in the low inclusiveness of social and business actors in territorial agenda. Both Polish and Lithuanian cases demonstrate the limited importance of civic and business actors in suburban policymaking but relatively high importance of local authorities. The local authorities tackle the ongoing tensions between the interests of different stakeholders. Although civic organisations are active in small-scale interventions, their voice in developing the territorial strategies remains almost unarticulated. Nevertheless, the problems of a shared definition of public interests, negotiations and business leadership create detached clusters within different suburban development visions. Besides, the interviewees seem not to expect the immense impact of actors who do not have an electoral mandate. The government (instead of governance) approach seems broadly accepted.

Secondly, the administrative self-governance design, decentralisation traditions and low level of institutional trust in the CEE region reflect the importance of vertical governance networks rather than horizontal. In both suburban localities, vertical and horizontal coordination networks are important as an interest's negotiation and decision-making mechanisms. However, the significance of vertical top-down networks (local-regionalstate) seems to have more power than horizontal ones. We expect that horizontal networks provide a formal basis for negotiations, consultancy and deliberations. The second problem is the diffusion of the different interest' groups and stakeholders with a diverse practice, understanding of the territorial needs and common good.

Thirdly, we consider the growing importance of designing territorialised agenda for urban-suburban relations. Our analysis confirms the low significance of state/regional authorities in designing and implementing urban-suburban interrelations policies. The orientation of local suburban authorities towards the metropolitan area is based on willingness, informal cooperation and territories' functional interconnectedness. The Lithuanian case reveals the dynamic nature of urbansuburban relations in terms of ongoing competition in attracting resources. In the Polish case, the municipality cooperates with the county and the region on a partnership basis. The explanation lies in the generally high institutional position of the municipal government in the national three-tier territorial governance system. The cooperation with the metropolitan area needs more compromise. The partisan context of intermunicipal cooperation is significant; for example, the authorities and mayors of the locality are associated with the leading national opposition party-the Civic Platform. The role of informal contacts and friendly relationships within a similar political environment enables the urban-suburban relations.

Finally, we must reconsider the nature of suburban governance and politics in the CEE region. There are consistent issues that differ in terms of the multiplicity of actors, institutions and interests. Intensive suburbanisation processes such as capital accumulation, decentralisation and the growing power of suburban political agendas allow re-imagining of local municipalities, regional authorities and states. Different suburban governance conceptions will enable us to discuss how to put into practice territory, collective action, networks and actors.

\section{Acknowledgments}

This project has received funding from the European Union's Horizon 2020 Research and Innovation programme, under grant agreement No. 727058. We would like to acknowledge our colleagues working with us on the COHSMO project, especially those who were involved in the Lithuanian and Polish case studies.

\section{Conflict of Interests}

The authors declare no conflict of interests. 


\section{References}

Atkinson, R., Tallon, A., \& Williams, D. (2019). Governing urban regeneration in the UK: A case of 'variegated neoliberalism' in action? European Planning Studies, 27(6), 1083-1106.

Bennett, R. J. (1997). Administrative systems and economic spaces. Regional Studies, 31(3), 323-336.

Blinnikov, M., Shannin, A., Sobolev, N., \& Volkova, L. (2006). Gated communities in the Moscow greenbelt: Newly segregated landscapes and the suburban Russian environment. GeoJournal, 66(1/2), 65-81.

Davoudi, S., Evans, E., Governa, F., \& Santangelo, M. (2008). Territorial governance in the making: Approaches, methodologies, practices. Boletín de la Asociación de Geógrafos Españoles, 46, 33-52.

Ekers, M., Hamel, P., \& Keil, R. (2012). Governing suburbia: Modalities and mechanisms of suburban governance. Regional Studies, 46(3), 405-422.

ESPON. (2014). Towards better territorial governance in Europe. A guide for practitioners, policy and decision makers based on contributions from the ESPON TANGO. European Spatial Planning Observation Network. Retrieved from https://www.espon.eu/ topics-policy/publications/guidance/towardsbetter-territorial-governance-europe

Faludi, A. (2012). Multi-level (territorial) governance: Three criticisms. Planning Theory \& Practice, 13(2), 197-211.

Florida, R. (2002). The rise of the creative class: And how it's transforming work, leisure, community and everyday life. New York, NY: Basic Books.

Healey, P. (1999). Institutionalist analysis, communicative planning and shaping places. Journal of Planning Education and Research, 19(2), 111-121.

Healey, P. (2004). Creativity and urban governance. Policy Studies, 25(2), 87-102.

Hess, D. B., Tammaru, T., \& Leetmaa, K. (2012). Ethnic differences in housing in post-Soviet Tartu, Estonia. Cities, 29(5), 327-333.

Hirt, S. (2007). Suburbanizing Sofia: Characteristics of
post-Socialist peri-urban change. Urban Geography, 28(8), 755-780.

Hirt, S., \& Petrovic, M. (2011). The Belgrade Wall: The proliferation of gated housing in the Serbian capital after Socialism. International Journal of Urban and Regional Research, 35(4), 753-757.

Jessop, B. (2000). Governance failure. In G. Stoker (Ed.), The new politics of British local governance (pp. 11-32). London: Macmillan.

Jessop, B. (2002). Liberalism, neoliberalism and urban governance: A state-theoretical perspective. Antipode, 34(3), 452-472.

Krisjane, Z., \& Berzins, M. (2012). Post-socialist urban trends: New patterns and motivations for migration in the suburban areas of Riga, Latvia. Urban Studies, 49(2), 289-306.

Ladner, A., Keuffer, N., \& Baldersheim, H. (2016). Measuring local autonomy in 39 countries (1990-2014). Regional and Federal Studies, 26(3), 321-357.

Le Galès, P. (2002). European cities: Social conflicts and governance. Oxford: Oxford University Press.

Lowndes, V. (2001). Rescuing Aunt Sally: Taking institutional theory seriously in urban politics. Urban Studies, 38(11), 1953-1971.

Rhodes, R. A. W. (Ed.). (2000). Transforming British government. London: Macmillan.

Sellers, J. M., \& Lidström, A. (2007). Decentralization, local government and the welfare state. Governance, 20(4), 609-632.

Stead, D. (2014). The rise of territorial governance in European policy. European Planning Studies, 22(7), 1368-1383.

Stoyanov, P., \& Frantz, K. (2006). Gated communities in Bulgaria: Interpreting a new trend in post-communist urban development. GeoJournal, 66(1/2), 57-63.

Swianiewicz, P., \& Lackowska, M. (2008). Cosmopolitans of small fatherlands. Miscellanea Geographica, 13(1), 197-208.

Young, D., \& Keil, R. (Eds.). (2010). In-between infrastructure: Urban connectivity in an age of vulnerability. Glasgow: Praxis Press.

\section{About the Authors}

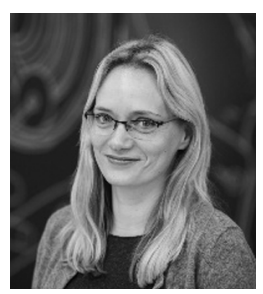

Jurga Bučaitè-Vilkè (PhD) is Associate Professor in the Department of Sociology, Faculty of Social Sciences, at the Vytautas Magnus University. Her research interests include local governance, local democracy and social policy areas.

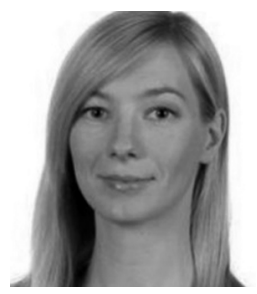

Joanna Krukowska (PhD) is Assistant Professor in the Department of Local Development and Policy, Faculty of Geography and Regional Studies, at the University of Warsaw. Her research interest is local and regional development policy, democracy and leadership. She has been working at the Ministry of Regional Development in Poland, in the media and for several NGOs. 